\title{
ENFERMAGEM TRANSCULTURAL E AS CRENÇAS, VALORES E PRÁTICAS DO POVO CIGANO
}

\author{
Cristiane Giffoni Braga*
}

BRAGA, C.G. Enfermagem transcultural e as crenças, valores e práticas do povo cigano.

Rev.Esc.Enf.USP, v.31, n.3, p. 498-516, dez. 1997.

Trata-se de um estudo mini-etnográfico em enfermagem, onde é enfocada a crença de cuidados, valores, modo de vida, visão de mundo de um grupo cigano de origem ROM. Foi utilizado o referencial teórico de LEININGER para auxiliar a compreensão desta cultura, visualizando propostas nas ações e decisões do cuidado de modo a prover cuidados culturalmente congruentes. Propõe a autora algumas definiçóes relativas à especificidade da cultura cigana no que diz respeito às formas culturais de prover cuidados, como subsidio para futuros estudos.

UNITERMOS: Enfermagem Transcultural. Cuidados. Crenças. Modo de Vida. Ciganos.

\section{1 - INTRODUÇÃO}

A identificação da natureza, essência e domínio da Enfermagem como profissão tem sido uma busca atual de pesquisadores em Enfermagem, através de suas produções científicas.

Tais atividades são relevantes para explicar o conhecimento e o avanço da Enfermagem e distinguí-la de outrás profissões. Estudos rigorosos atentam para a natureza e o fenômeno do cuidado, sendo este humanizado.

Este fa to é confirmado por LEININGER (1981), quando declara: "o cuidado é o domínio central e o único para o corpo de conhecimentos e prática na Enfermagem, e uma investigação sistematizada do cuidado poderá avançar a disciplina de Enfermagem e em último caso, prover cuidados de enfermagem melhores para o povo".

LUNA CAMERON (1989), descrevendo a teoria de LEININGER, afirmam que "a Enfermagem é essencialmente uma ’rofissão de cuidados transculturais, a única que se centra na promoção do cuidado humano para pessoas de uma maneira significativa, congruente, respeitando os valores culturais e estilo de vida".

* Enfermeira. Docente - Escola de Enfermagem Wenceslau Braz, Itajubá - MG. Mestranda em Fundamentos de Enfermagem - Escola de Enfermagem da USP. 
Com base nestas considerações e analisando a teoria transcultural de LEININGER: Diversidade e Universalidade do Cuidado, busquei estudar um povo que nos atrai e fascina pela cultura, pelo seu modo exótico de ser e de existir, perpetuando-se através dos tempos: o povo Cigano.

A falta de artigos de enfermagem enfocando os ciganos, leva esta profissão a se distanciar dessa cultura minoritária; devido em parte também aos mitos que a envolvem, o que dificulta a provisão de cuidados específicos no caso. Isso se confirma por BODNER LEININGER (1992).

\section{2 - OBJETIVO}

A finalidade do estudo é enfocar a crença de cuidados, valores, práticas, modo de vida, visão de mundo de um grupo cigano, de origem ROM , para auxiliar a enfermagem na compreensão desta cultura, de modo a prover cuidados culturalmente congruentes.

\section{3 - PERSPECTIVA TEÓRICA}

LEININGER (1985a), com sua Teoria Cultural do Cuidado, propiciou condições para estudar uma comunidade cigana, por ser uma teoria de Enfermagem Transcultural, a qual provê uma estrutura holística e compreensiva para examinar sistematicamente diferentes dimensões da cultura, dentro de uma perspectiva de Enfermagem.

A teoria de LEININGER foi desenvolvida a partir da Antropologia; porém, reformulada para Enfermagem Transcultural com perspectivas de cuidado humanizado.

LEININGER, citada por ALEXANDER, J. et al (1989), desenvolveu métodos de pesquisa em etno-enfermagem, e tem enfatizado a importância de estudar um povo sob uma perspectiva "emic" e "etic", usando um método de pesquisa qualitativa para a descoberta de características universais e de diversidade da cultura em estudo.

Uma perspectiva "emic" refere-se à forma pela qual os próprios membros da cultura percebem seu mundo.

Uma perspectiva "etic" é a interpretação das experiências daquela cultura, a partir de fatos pesquisados.

LEININGER tem sido habilidosa em usar a etno-enfermagem, a etnografia e o método de observação-participante - O-P-Rmodel - preconizado por esta, consistindo no processo de observação, participação e reflexão. Este método direciona para uma visão holística ao estudar o comportamento humano nos diversos contextos ambientais. 
O pesquisador obtém dados de documentação descritos dos informantes que realizaram, observaram e verificaram um determinado comportamento identificando assim, a essência da natureza, o processo e atributos do comportamento cuidador e terapêutico do cuidado de enfermagem dentro da cultura.

Esta direção é importante para o desenvolvimento básico de conhecimentos sobre o cuidado para que se possa guiar a prática da Enfermagem explicitada pela autora.

Neste estudo foi desenvolvida a fase de observação, acrescida da entrevista com relativa participação da autora, visto que o objeto do estudo foi promover a compreensão da cultura cigana .

\section{4 - A TEORIA TRANSCULTURAL DE LEININGER}

A Teoria do Cuidado Transcultural citada por LEININGER (1985a) enfatiza que há diversidades no cuidado humano, com características que são identificáveis e que podem explicar e justificar a necessidade do cuidado transcultural de enfermagem, de forma que este se ajuste às crenças, valores e modos das culturas, para que um cuidado benéfico e significativo possa ser oferecido.

Os atos do cuidado cultural que são congruentes com as crenças e valores do cliente são considerados como sendo o conceito mais significativo, unificador e dominante para se conhecer, compreender e prever o cuidado terapêutico popular.

O cuidado baseado culturalmente é o fator principal e significativo na afirmação da Enfermagem como curso e como profissão, e no fornecimento e manutenção da qualidade do cuidado de enfermagem prestado aos indivíduos, às famílias e aos grupos comunitários.

LEININGER (1983) declara "o cuidado como centro, único e dominante foco característico da Enfermagem".

O cuidado cultural, ainda referendando a autora, significa "avaliação consciente e um esforço deliberado para usar valores culturais, crenças, modo de vida de um individuo, família ou grupo comunitário, para fornecer auxílio significativo para estas necessidades de cuidado nos serviços de saúde".

LEININGER (1984 c.p.42), segundo LUNA CAMERON (1989), refere que "culturalmente as ações de cuidado de enfermagem e intervenções são previsíveis para manter a saúde do cliente, fornecer satisfação e ajudá-lo a se recuperar de doenças ou incapacidades. O cuidado culturalmente congruente pode também ajudar clientes face à morte de modo significativo e pacífico".

Desta forma a Enfermagem tem como foco segundo LEININGER, citada por GUALDA; HOGA (1992), "o estudo da análise comparativa de diferentes culturas ou subculturas no que diz respeito ao comportamento relativo ao cuidado 
em geral, ao cuidado de enfermagem, assim como aos valores, crenças e padrões de comportamento relacionados a saúde e doenç". Essa autora afirma ainda que "o objetivo da enfermagem transcultural vai além da apreciação de culturas diferentes, mas de tornar o conhecimento e a prática profissional culturalmente embasada, conceituada, planejada e operacionalizada. Se aqueles que praticam a enfermagem não considerarem os aspectos culturais da necessidade humana, suas ações poderão ser ineficazes e trazer conseqüências desfavoráveis para os assistidos".

Com o objetivo de facilitar a compreensão do conjunto de elementos que compõem a teoria de LEININGER, GUALDA; HOGA (1992) fizeram a tradução dessas conceituações elaboradas por LEININGER.

Serão descritos a seguir, apenas os conceitos que fundamentaram a compreensão do estudo:

CULTURA - Valores, crenças, normas de comportamento e práticas relativas ao estilo de vida, aprendidos, compartilhados e transmitidos por um grupo específico, que orientam o pensamento, as decisões e ações dos elementos pertencentes ao grupo.

VISÃO DE MUNDO - Modo como os indivíduos percebem seu mundo e universo, e nele inserem sua perspectiva de vida.

ESTRUTURA SOCIAL - Processo dinâmico e de natureza interdependente, compreendendo elementos estruturais ou organizacionais da sociedade e o modo como esses interatuam e funcionam. Incluem os sistemas religioso, familiar, político, econômico, educacional, tecnológico e cultural, delimitados pelo contexto lingüístico e ambiental.

No âmbito deste trabalho, o CUIDADO, definido como "fenômeno de assistência, apoio ou facilitação a outro indivíduo ou grupo com necessidades antecipadas ou evidentes, com a finalidade de melhorar a condição humana ou o estilo de vida," será o objeto central a ser pesquisado.

LEININGER, citada por GUALDA; HOGA (1992), "acredita que a teoria transcultural seja capaz de predizer e explicar os padrões de cuidado humano das diversas culturas, bem como possibilitar a identificação de valores, crenças e práticas populares pelos profissionais de enfermagem". Acredita ainda que "por meio deste conhecimento, as decisões'e ações de enfermagem podem tornarse congruentes e benéficas para aqueles que são assistidos. Na análise da abordagem de enfermagem, distingue três formas de atuação:

* Preservação Cultural do Cuidado: fenômeno culturalmente embasado, de assistir, facilitar ou capacitar o indivíduo, que o auxilia a preservar ou manter hábitos favoráveis de cuidado e de saúde.

* Acomodação Cultural do Cuidado: ato, culturalmente embasado, de assistir, facilitar ou capacitar, que revela formas de adaptação, negociação ou ajustamento dos hábitos de saúde e de vida dos indivíduos ou clientes. 
* Reestruturaçáo Cultural do Cuidado: modelos reconstruídos ou alterados para auxiliar o cliente a mudar os padrões de saúde ou de vida, de forma a tornar significativo ou congruente para ele próprio".

\section{OS PRESSUPOSTOS BÁSICOS DA ENFERMAGEM} TRANSCULTURAL que desafiam a Enfermagem a descobrir em profundidade o fenômeno do cuidado, segundo LEININGER (1981), são:

* o cuidado humano é um fenômeno universal, mas a expressão, o processo e o modelo variam entre as culturas;

* cada situação de cuidado de enfermagem tem comportamento no cuidado transcultural, necessidades e implicações;

* o ato e processo de cuidar são essenciais para o desenvolvimento humano, crescimento e sobrevivência;

* o cuidado poderá ser considerado a essência e unificação intelectual e dimensão prática do profissional de enfermagem;

* o cuidado tem dimensões biofísicas, psicologicas, culturais, sociais e ambientais, as quais puderam ser estudadas, praticadas no sentido a prover cuidado holítisco para as pessoas;

* o comportamento de cuidado transcultural, formas e processos tem ainda que ser verificado em diversas culturas, quando este corpo de conhecimento é obtido, tendo potencial para revolucionar a prática diária da enfermagem;

* para fornecer cuidado de enfermagem terapêutico, a enfermeira poderá ter conhecimento de valores culturais, crenças e práticas dos clientes;

* os comportamentos de cuidados e funções variam de acordo com características da estrutura social de determinada cultura;

* a identificação de comportamento universal e não universal, cuidado popular e cuidado profissional, crenças e práticas, serão importantes para 0 avanço do corpo de conhecimentos de Enfermagem;

* há diferenças entre a essência e as características essenciais de cuidado e comportamentos de cura e processos;

* não existe cura sem cuidado, mas pode existir cuidado sem cura.

SUNRISE MODEL - LEININGER (1985b), traduzida por GUALDA; HOGA (1992), propôs modelo que denominou Sunrise Model, simbolizado pelo nascer do sol, no sentido de auxiliar a análise do significado do cuidado para diversas culturas. Este modelo considera a operacionalização de teoria e pesquisa e orienta o estudo da diversidade e universalidade do ato de cuidar. Através dele o pesquisador determina a abrangência e a profundidade do estudo. Combina teoria e método de pesquisa e distingue níveis de abstração e análise, assim como a abordagem metodologica na geração de conhecimento básico e aplicado.

A porção superior do círculo mostra os componentes interdependentes da estrutura social e dos fatores da visão do mundo que influenciam o cuidado e a 
saúde por meio da linguagem e do contexto ambiental. Esses fatores influenciam o sistema de saúde, compostos pelo sistema popular, profissional e o de enfermagem que se encontram na parte inferior do modelo. As porções superiores e inferiores descrevem um sol completo que corresponde ao universo; este precisa ser explorado pelas enfermeiras para que conheçam o cuidado humano e sua relação com a saúde.

A esquerda do diagrama estão dispostos os diversos níveis de abstração e análise do cuidado: macro, médio e micro referem-se à abrangência do estudo do cuidado. Níveis de abstração e análise são classificados em I, II, III, IV, correspondendo o nível I ao de maior abstração e o nível IV ao de menor.

O nível I engloba o sistema social e a percepção do mundo.

No nível II, são estudados o cuidado e a saúde, e incluem os indivíduos, famílias e culturas no contexto de um sistema de saúde, em busca de seus significados e de suas expressões.

No nível III são estudados os sistemas profissional e popular, na busca de características e aspectos específicos de cada sistema, com a finalidade de serem determinadas as áreas de semelhança e diferença.

No nível IV é utilizado para que seja desenvolvido um tipo de cuidado de enfermagem congruente com as culturas e por estas valorizado.

Ao lado direito do modelo está especificado o conhecimento que pode ser básico ou aplicado a situações práticas referentes ao cuidado universal e específico, gerado das teorias e pesquisas. Sem o conhecimento científico básico e humanístico a Enfermagem não se pode estabelecer como profissão. 


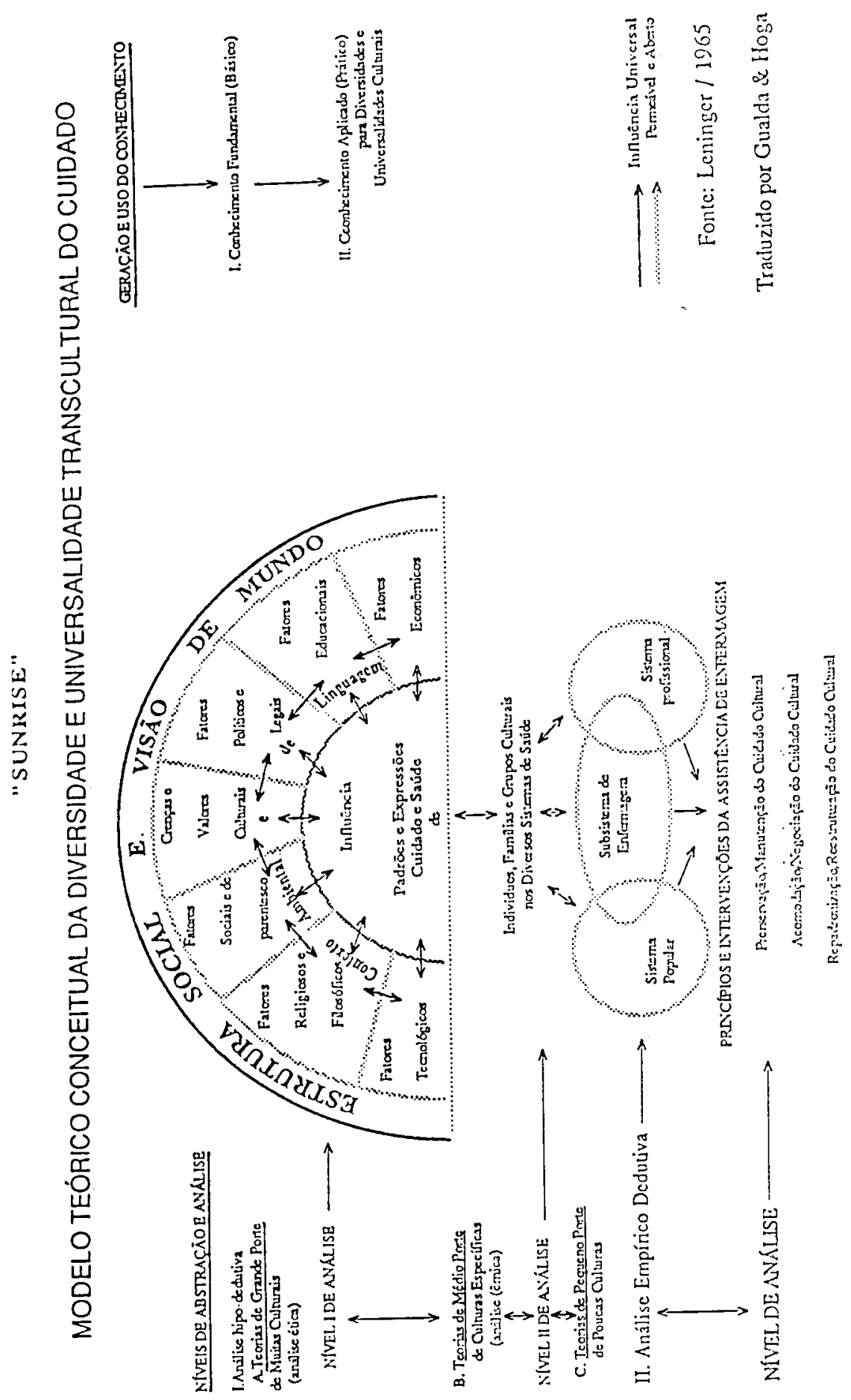




\section{5 - FASES DO ESTUDO}

Trata-se de um estudo mini-etnográfico em enfermagem, que LEININGER define como "o estudo e a análise de visões, crenças e práticas de pessoas do local ou nativas, sobre o comportamento de cuidado de enfermagem e processos de cultura específica, onde o enfoque está no domínio da cultura, cuidados e valores, expressões e significados de um povo cigano".

Foi enfocada uma família cigana, de origem ROM, constituída de seis pessoas, sendo elas a Bába, o marido e a mulher, a prima e duas crianças, filhos deste casal. A informante chave foi a prima.

A seleção da informante chave ocorreu de forma natural ; pois esta tinha facilidade de expressão, maior disponibilidade e interesse em compartilhar dados de sua vida cigana ; participando do estudo. Foram necessárias três sessões para a realização da fase de observação, sendo que a primeira sessão foi para conhecer o ambiente, a família, construindo um clima de confiança entre os ciganos e o profissional.

Essa primeira sessão foi no dia da Festa de Nossa Senhora de Fátima, motivo de grande festa para os ciganos; a religião é sagrada para eles. Apenas me apresentei; disse meu propósito de trabalho, embora quase não dessem importância, devido à festa, e ao fato de o chefe não estar lá, portanto, não haver permissão para a entrevista. Senti um clima de desconfiança em relação à minha pessoa; olhavam-me atentos, observavam minha atitude, pois embora tendo sido negada a realização para a entrevista, o convite para ficar na festa foi feito.

Na segunda sessão, com permissão do chefe para efetivar meu trabalho, ainda com olhares atentos, porém menos desconfiados, fiquei a tarde inteira no acampamento, onde conversamos bastante e gravei a entrevista. Esta foi conduzida de maneira natural, informal, com perguntas abertas fundamentadas na proposta de LEININGER. Tive no entanto que dizer, antes de ligar o gravador, as perguntas que faria.

Durante todo o tempo da entrevista com a informante-chave, todos ao redor me olhavam com atenção. A conversa esteve mais aberta antes que eu ligasse o gravador, até mesmo com a Bába, que menos falava com estranhos denominados por eles de "Gadjês".

$\mathrm{Na}$ terceira sessão, com a confiança relativamente já conquistada, houve trocas de presentes e um laço de amizade foi estabelecido.

A descrição dos dados foi efetuada de forma detalhada, inclusive a transcrição de diálogos.

A análise dos dados que constam neste relato foi feita de acordo com o modelo Sunrise, de LEININGER (1985b).

O material coletado foi analisado de acordo com os seguintes passos: 
a) Mapeamento dos registros segundo variáveis da estrutura social, percepção de saúde e doença, e ainda cuidados de manutenção, acomodação e repadronização.

b) Agrupamento do que se considera exemplos mais significativos dos dados levantados.

c) Organização na forma discursiva desses dados.

O anonimato da família cigana foi resguardado.

\section{6 - A CULTURA CIGANA}

Dados etno-históricos segundo GROPPER apud BODNER;LEININGER (1992) atribuem a paternidade dos ciganos aos DOM, tribo que existiu na Índia, no século IV. O certo é que, até o século XV, os europeus presenciaram com assombro a aparição de diversos grupos estranhos, sempre vestidos de maneira ex6́tica, provavelmente chegando à Europa através da Pérsia e da Armênia. O termo "Gypsy" acredita-se ter vindo do Egito.

Segundo GARCIA (1995), "o Tronco do Povo Cigano está na India, seus ramos estão espalhados pelo mundo afora e suas raízes chegam até o Patriarca Abraão e todo o seu povo andante. Existem várias raças ou nações ciganas, com costumes e tradições fortes e semelhantes. As diferentes raças se originaram de dois grandes grupos: ROM e KALON. Daí existirem por exemplo, Calderasha, Lovara, Maçvais, Moldovais, Horohané, Gorbeta, Doreski, Chucureski, Puroneski, os Sinti e muitos outros. Deram origem aos Circos e Parques de Diversões e são grandes artistas de palco e picadeiro. Inspiraram muitas óperas, danças e balés no mundo in teiro".

\section{7 - VIVENCIANDO O CUIDADO}

\section{a) Conhecendo o ambiente e identificando a família:}

O acampamento cigano situava-se em um terreno baldio na periferia de uma cidade no interior de Minas Gerais. Era composto de duas tendas, a maior e mais completa chamada Tchera, onde todo o chão era forrado com tapetes coloridos, tendo ao centro uma pequena mesa redonda com uma vela acesa e três imagens de Nossa Senhora Aparecida - santa de devoção - representạndo a presença de três famílias, a saber: a Bába, a prima, o marido - filho do chefe. Ao fundo havia seis cavaletes para levantar travesseiros e cobertores, uma TV e

${ }^{1}$ GARCIA, P.- Padre Missionário da Pastoral dos Nômades, reconhecida pela Igreja Católica. 
rádio. Do lado esquerdo, uma mesa para refeições e um pequeno fogão; do lado direito, mais para a frente da tenda, uma pequena fogueira e algumas cadeiras. O espaço entre os cavaletes e a lona era destinado para o banho, sendo gramado. Próximo a esta tenda havia uma mesa com bacias de água, tachos e louças secando ao sol. A tenda menor, quase em frente dessa, era principalmente destinada à fabricação e conserto de tachos e panelas, que eram comercializados com os Gadjês - termo usado pelos ciganos, atribuído às pessoas não ciganas, estranhas à cultura deles.

Cercando o acampamento haviam três carros do ano. O sanitário localizava-se atrás da tenda, sendo em sistema de fossa.

Nessa família, representada pela Bába, ela, a prima e o marido moravam juntos há tempo; o senso de união era dominante, embora tivessem imagens da Santa de devoção representando cada família. A Bába era uma senhora de setenta anos, de cabelos grisalhos, com brincos e colares. Vestia blusa e saia estampada e bem rodada. Quase não falava português e sim o romanês, e não me dirigia a palavra, porém ficava sempre, com um cigarro, observando. Para os presentes era tida como "a poderosa". Além do imenso respeito aos velhos os ciganos têm profunda obediência à Bába pela sua sabedoria.

A prima era moça de cabelos loiros tingidos, sempre com um lenço bordado no cabelo que logo me disse: "quando uma cigana não é mais virgem, ela carrega esse lenço para sempre como sinal". Tinha um vocabulário que poderia se chamar elaborado, ciente dos problemas atuais, das inovações do mundo. Era cativante, falante. Às vezes era chamada sua atenção pela Bába no tocante as suas colocações. Suas roupas eram "exóticas" por serem coloridas, estampadas e de modelos variados. O marido e a mulher eram moços ainda, demonstravam reserva, porem de uma forma discreta observavam as conversas. A mulher em afazeres domésticos quando abordada "por mim" pensava antes de falar, sempre dando a impressão de "mistério". O marido, arrumando os tachos, tinha pulseira e corrente dourada no pescoço. Os filhos do casal, eram dois meninos muito ativos, com idade variando de nove a catorze anos. O mais velho já dirigia carro, pois segundo o pai "já era homem".

\section{b) Percebendo a visão de mundo e perspectiva de vida:}

A informante afirmava que "no mundo dos brasileiros, dos Gadjês, há muita falta de dignidade, de honestidade, de amor próprio; porque as pessoas só podem amar o próximo quando se amam e no meio dos brasileiros são muito poucos os que amam a si mesmos"... "a nossa família ROM, cigano, é muito unida. Não existe desunião no meio cigano - por exemplo, se um inimigo estiver doente, eu vou ajudar ele a se levantar e depois que ele se levantar, aí sim, viramos inimigo de novo; mas enquanto ele estiver caído não tentamos pisar um no outro, temos respeito proprio".

Assim, afirma LEININGER apud BODNER; LEININGER (1992), “... sua visão de mundo e uma força para sustentar a identidade cultural e auto-estima; identificou-se a visão de mundo dos ciganos como a maneira de uma cultura se 
guardar e ver o mundo e o universo". Em relação à perspectiva de vida foi dito: "nós temos nossa vida muito unida, compreende; cada um tem seu mundo, respeita seu espaço; nós somos todos unidos numa só maneira. Quando o chefe dá uma ordem nós temos que cumprir, sendo a família qual for. Se aqui tivessem dez barracas e o chefe mandasse, nós levantaríamos o acampamento, compreende".

Os ciganos, segundo BODNER; LEININGER (1992), "são altamente conscientes de seu modo e estilo de vida para manter a sobrevivência cultural... Como um povo, eles não têm um país próprio de ficar, mas têm sua identidade cultural fixa".

O valor cultural exerce influência marcante nesta cultura, destacando-se a valorização da família, da união e do respeito.

\section{c) Conhecendo o modo de vida:}

"... Nosso dia-a-dia, graças a Deus, é muito alegre", contava a informante. "A gente levanta com rádio ligado, dança, é alegre em nossas festas; por exemplo: os brasileiros se apaixonam pelo lado de fora, vendo, e não têm isso, se uma pessoa chegar ela é bem recebida, seja ela o que for".

"Normalmente acordamos às 6 horas e as mais velhas às 4 horas; porque quem cedo madruga, Deus ajuda. O café é no máximo até $8 \mathrm{~h}$ e $30 \mathrm{~min}$. Tomamos chá com frutas, café, comemos um bolo que é feito pela Bába, chamado "Guibanitcha", que contém ovo, ricota, passas ao rum e a farinha de trigo, que representa fartura. Após o café a gente vai trabalhar, lê a sorte. A Bába diz o dia em que temos vidência mais forte, cada uma tem um dia. Então vou cedo à rua ler a sorte; fico até 3 ou 4 horas e depois volto para fazer a janta, que é servida alí pelas 5 ou 6 horas. Depois conversamos e vamos dormir".

Quanto à alimentação, comiam com freqüência nas refeições grande quantidade de pimenta; ... "dá um tempero bom". Nas festas eles comem o carneiro, que representa fartura, agradecimento; a cigana diz: "e o bicho mais limpo e também porque é de Deus; antigamente se faziam sacrifícios". As frutas são variadas e servem de decoração; tem o bolo da Bába, porco, charuto, que para os ciganos se chama "Sarne". As bebidas são: chopp, vinho e uísque.

Os trajes são os mais coloridos possíveis com uso de muitas jóias, o que representa para o cigano "amuleto", é sagrado e passa de geração em geração.

As mulheres vestem-se em dias normais de saia e blusa "Tchupaco", em respeito aos mais velhos que estão no acampamento, e os homens de calça e camisa.

Nota-se que esta cultura valoriza a preservação de seus costumes e tem grande senso de pudor e respeito para com os mais velhos no acampamento, assim como na preservação de seus hábitos alimentares, costumes e suas crenças, levando-os a se afastar de outras culturas, na minha opinião. 


\section{d) Conhecendo a situação econômica:}

Observa-se nesta cultura que os ciganos têm sua economia bem agenciada, isto é, bem gerida na opinião dos ciganos, o que pode ser verificado nas falas da informante: "Nós somos pessoas econômicas, porque o dinheiro chama o dinheiro, temos nossos carros do ano, nossa TV, nossas casas..., a gente toma conta disso tudo muito bem; pagamos impostos como pessoa normal; só que o nosso dinheiro é bem rendado; compramos casas e joias. Nossas casas são espaçosas, porém gostamos de liberdade, de não nos sentirmos presos, aí moramos em barracas".

Foi possível captar que as ciganas usam dos recursos da natureza e praticam a leitura das mãos como fonte econômica, e os ciganos com o mesmo fim, fazem conserto e comércio de tachos e panelas.

A renda é distribuída de maneira adequada, contemplando a todos. A situação econômica do grupo lhes permite acesso às comodidades trazidas pela tecnologia.

\section{e) Conhecendo o aspecto legal e a justiça:}

Percebe-se que os padrões culturais, modo de vida e valores são cercados de um certo autoritarismo por parte da "Bába", do "Chefe" e da "Kris Romani", fato que os mantém unidos através dos tempos, o que se nota nos dizeres da informante: "quem decide o lado da justiça é o chefe e as pessoas mais velhas, mais sábias. Eles se juntam e fazem o Kris Romani para saber certinho quem é que fez o errado, pois será punido. Por exemplo, se ofendeu algum outro, se passou o outro para trás, essa pessoa fica sem ser respeitada, não é mais respeitada no mundo cigano e paga uma multa de vergonha que para vocês chama indenização, para nós chama multa e paga em moeda de ouro".

Observa-se que a "política adotada" é fortemente enraizada nesta cultura, sendo um domínio marcante na vida dos ciganos, preservando-os da cultura dos Gadjês. Percebe-se que os ciganos freqüentemente discriminam os atos dos Gadjês, fazendo julgamentos sobre seus valores culturais.

\section{f) Conhecendo o parentesco e o fator familiar:}

Neste contexto cultural os valores do casamento, virgindade, família, são marcantes; possuem seu mérito na proporção direta da importância que se atribui a cada um deles.

Isto é fortemente marcado nos dizeres da informante:

"No meio cigano a pessoa já nasce sabendo que vai casar com uma determinada pessoa. Você tem que procurar nessa pessoa o que ela tem de bom e não ver o que é ruim... A mulher no meio cigano é muito inteligente, ela sabe contornar qualquer situação"... "Atrás de grandes homens existem grandes mulheres"... "Não tem esse negócio de antes do casamento sair, paquerar, namorar e às vezes 
até dormir juntos".. "Para o cigano a virgindade é sagrada. Se a moça não for virgem é a maior vergonha que existe no mundo, para o pai dela, mãe, avós e para os que já morreram. Ela precisa ser virgem porque é a coisa mais bonita que uma moça pode entregar para o sogro, para o marido"...

"Quando a mulher casa, ela vai morar com a família do marido, onde ela cumpre uma série de obrigações para com o esposo e familia, servindo-os".

Desta forma, percebe-se que a mulher no meio cigano é submissa, logo cedo, em criança já aprende o estilo de vida e habilidades, adotando comportamento determinado pela cultura. Essa condição imposta pela cultura, seguindo obrigações é aceita passivamente.

A valorização da criança como futura geração, perpetuando crenças e valores, é razão para a não aceitação de métodos anticoncepcionais no acampamento.

As crianças são atendidas em especial e tratadas como miniaturas de adultos. Não há possibilidade, na família, de desunião; o laço familiar é mantido e valorizado.

\section{g) Conhecendo a linguagem e educação:}

A língua cigana falada por toda a sua nação é o Romanês (filha do Sânscrito da Índia). O Sânscrito, segundo FREI FERNANDES", "deu origem às seguintes línguas modernas da India, a saber: Hindi, Rajastani, Pahari, Gujarati, Romanês, Kashmiri, Kohistani, Landa, Sindi, Marati, Bihari, Oriijá, Bengali, Assamese, Nepalês".

O idioma cigano é fator que contribui para defesa dos ciganos no mundo dos Gadjês, sendo passado de geração em geração, oralmente. Segundo DENHAM apud BODNER; LEININGER (1992), "porque o Romanês não é uma língua escrita, nenhum documento ou registro tem sido preservado pelos ciganos. Entre eles só é falado o Romanês, podendo-se identificar um forte valor cultural e o uso da linguagem como proteção".

Quanto à educação, a cigana colocava: "mesmo que um cigano seja analfabeto e você vai fazer conta com ele, você não consegue; ele faz mais rápido que você. Porque o cigano é muito rápido em fazer conta, eles são muito inteligentes; principalmente as crianças. Como a criança aprende dois dialetos, você já vê que ela é bem mais inteligente; então, quer dizer que é fácil ela aprender as coisas. Depois dos sete, oito anos, ela vai para a escola e fica até os treze, catorze anos no máximo, seja homem ou mulher. O homem se quiser pode ficar mais um pouco; não tem problema, mas a mulher, não. Ela tem obrigações em casa".

${ }^{2}$ FERNANDES, T. Pe. e Frei - Missionário da Pastoral dos Nômades. 
Isto se confirma por LEININGER apud BODNER; LEININGER (1992) : "Como eles não honram as regras e costumes, eles não ficam preocupados e atentos às regras que requerem para seus filhos em freqüentar escolas".

A educação formal é um traço cultural que penso ser menos significante para esta cultura.

\section{h) Conhecendo a religião:}

A religião no meio dos ciganos representa a vida; é fator dominante nesta cultura. Segundo GROPPER apud BODNER; LEININGER (1992), "o domínio religioso é fator predominante na vida cigana".

Isto se confirma nos dizeres da informante: "Se você confia em Deus, Ele vai te libertar de todos os males. Se não confia Nele, em quem você vai se segurar? Em nada! Nós confiamos em Deus porque Ele é onipotente, rege todo tipo de família é o Pai de toda a geração... Deus é onipotente, Deus fez a terra, o mar, o ar; fez tudo tão bonito para a gente. A gente acredita também muito em Nossa Senhora de Fátima e Nossa Senhora Aparecida, que em Sevilha, é chamada de Santa Sara... Como todo ano, fazemos promessas para Ela e todas as nossas promessas, graças a Deus, são aceitas. A gente paga a promessa e dá tudo certo... Pagamos fazendo festas; onde cada ano aumenta mais para Nossa Senhora Aparecida, bem mais"...Quando armamos uma tenda, a gente fala assim: Querbartolotã, significando benção pedida para dar sorte onde a gente está armando".

No tocante à morte, ..." ela trás muito sofrimento ao cigano, tanto para a familia como para a pessoa que foi; é muito triste. Nós ficamos de luto; alguns por 41 dias, mas outros por 7 dias. Nestes dias não vemos $T V$, não fazemos espuma-porque a água com sabão quer dizer limpeza, alegria e não estamos no periodo de alegria. Nossas roupas, vestimos da mesma forma, só que menos florida. Alguns homens usam uma fita preta na camisa avisando que estão de luto; para respeito. O período de luto representa 7 dias que aquela pessoa morreu; você joga um pouco d'água na grama e canta uma música que ela gostava; isso significa que você jogou o luto, aí, até $4 l$ dias você coloca água para ela. Todo cigano vem de manhã na barraca, coloca um copo de água para ela e antes de beber derrama um pouco no chão; isto significa respeitando a pessoa que morreu. Depois dos 41 dias todas as roupas e objetos pessoais que ela tinha é jogado numa água corrente, para as águas levarem para ela. No caixão é colocado uma muda de roupa para ela porque ela vai andar 41 dias e depois ela vai e nunca vai mais volta".

Verifica-se assim que o cigano não utiliza o sabão para banhos e higienização em geral, respeitando inclusive os mortos quando não se procede ao preparo corporal com sabão. 


\section{i) Percebendo a visão de saúde e doença:}

A estrutura social e cultural em que vive esta família de ciganos influencia a forma como percebem a saúde e a doença.

A informante declara: "Nós temos muito cuidado com a saúde. Graças a Deus todo mundo se cuida, mas quando há problema de coração ou úlcera, que existe em nossa família, ou nascimento de uma crianca, a gente vai ao hospital, procuramos um cardiologista e endoscopia. É lógico que a gente vai tentar 0 médico, porque estamos no século $X X$, tentamos o que for melhor. $O$ médico estuda tantos anos, então ele sabe mais do que a gente, fala a verdade".

Este fato é confirmado por LEININGER apud BODNER; LEININGER (1992): "os ciganos vêem o cuidado de saúde por profissionais somente quando eles têm uma situação súbita, uma emergência que eles não podem resolver".

Embora diante desta consideração, a informante afirma que os ciganos fazem prevenção de algumas doenças, que não foram explicitadas .

Quando doentes, os ciganos comem de tudo, porém no início é oferecida canja de galinha. Não trabalham, ficando em repouso e a Bába preparando chás.

Quando a ajuda por profissionais de saúde é solicitada, significa que todo o possível já tinha sido feito. É relatado que alguns médicos, profissionais de saúde e enfermeiras os tratam muito bem: "talvez porque estão lá para ajudar, somente alguns".

Ao ser admitido um cigano no hospital a informante coloca: "se um cigano fica no hospital, todo o clã fica do lad, de fora; meu pai faleceu e antes de morrer ficou 35 dias no hospital e toda a família ficou lá de fora. O hospital não nos impediu porque estávamos fora, nos carros. Ali a gente almoçava, jantava, dormia. Era preciso ficar porque uma pessoa especial da familia estava lá dentro sofrendo, doente. Ela precisava saber que estava todo mundo lá fora... Às vezes só podia subir uma pessoa no CTI, a gente dava um jeitinho e subia de dois e três; sempre tem um jeitinho".

Observa-se que tal fato LEININGER apud ANDERSON ; TIGHE, (1973) em estudo de etno-enfermagem com os ciganos do Noroeste dos Estados Unidos, percebeu: "Os ciganos causam sérias dificuldades para a administração hospitalar e enfermagem quanto às normas a serem seguidas".

A informante continuou: "Meu pai não tinha mais vida, estava vivendo à base de aparelhos, remédios e drogas; alguns queriam tirá-lo assinando termo, mas o médico disse que ele poderia morrer na estrada. Então, falamos para o doutor que se é no hospital o melhor, então tire ele do CTI e coloque num quarto e todo mundo vai entrar".

"No quarto o doutor insistiu em um de cada vez; esse um era cinco de uma vez só. Ali a gente levava todo o tipo de comida, bebida, não podia, mas nós levávamos. Se ele não vai ter vida, então ele tinha que aproveitar um pouco de vida que restava para sentir no meio dos ciganos. A gente rezava muito... A junta médica e enfermeiras, viram nossa aflição e liberaram nossa entrada porque 
disseram que às vezes, quem sabe, esses poderão adoecer por causa de um paciente s6".

LEININGER recorda que "como uma enfermeira transcultural, era freqüentemente chamada para lidar com esses problemas culturais".

No tocante às medicações vê-se que os ciganos ROM têm sua própria medicação, à base de ervas e plantas medicinais; porém, os nomes e finalidades são guardados em segredo pelos ciganos. Tal fato não ocorre, segundo FERNANDES (1996), com os Kalóns; "estes comercializam suas ervas".

Em relação aos Serviços de Saúde, os ciganos não procuram os Postos de Saúde alegando não darem atendimento. Pela possibilidade, procuram Hospitais como o Albert Einsten, Beneficência Portuguesa, Instituto do Coração em São Paulo, onde colocaram: "o mundo é movido a dinheiro. Se paga, tem atendimento". Tal fato é verificado por ANDERSON; TIGHE, (1973).

Quanto ao fato da gravidez, é relatado que a mulher cigana, mesmo sabendo que está grávida, faz exame de sangue e tem acompanhamento pré-natal e no nascimento por profissionais de saúde. Durante os 9 meses ela não trabalha, não carrega peso, é mimada, justificando-se pelo fato de que espera uma futura geração. $O$ ultra-som é determinante em valor, caracterizando-se como uma tecnologia de valor reconhecido para os ciganos. "Todo mundo vai ao hospital para o ultra-som; para saber se é menino ou menina. Se menino, a euforia é maior, ganha uma moeda de ouro porque o homem é que tem força, manda mais no meio cigano; se menina, ganha algum presente dos pais".

Pode-se perceber a mulher como atributo menos valorizado no meio cigano em relação ao comando e força.

Depois que a mulher tem o filho, ela fica em um tipo de mosquiteiro chamado de "Polô". Ela entra em um período de "marimê" por 41 dias, que significa um período pós-parto em que a mulher está poluída, necessitando passar por um "ritual de purificação", ficando separada, isolada do povo cigano; deitada, recebendo cuidados da sogra até o $10^{\circ}$ dia. Após o $10^{\circ}$ dia ela levanta, toma seu banho, veste as roupas e vai fazer a festa da criança. GROPPER apud BODNER; LEININGER (1992), declara que "durante o período de marimê, rituais de separação são praticados como medida de proteção e de bem-estar dos ciganos".

Observa-se em relação à alimentação do bebê uma preservação de cuidado de grande valor: "a criança se alimenta do leite da mãe mesmo. Não esse negócio de mamadeira. A criança precisa de muita força e a única força que a mãe pode dar é o leite. A mãe quando tem um filho tem que sacrificar por ele ao máximo".

\section{8 - ANALISANDO A EXPERIÊNCIA}

De acordo com o referencial utilizado, busquei compreender a influência da estrutura social e cultural, o processo saúde-doença e as práticas do cuidado dos ciganos. 
Os dados relativos à visão de mundo, religião, valores culturais, legais, parentesco e práticas gerais de cuidados e seus rituais foram as características principais identificadas nesta comunidade, podendo ser os suportes utilizados pela enfermagem para prestar cuidados de enfermagem congruentes com os valores culturais que tenho estudado.

A Enfermagem deve conhecê-los para assim buscar formas de cuidar, guiando-se pela compreensão para as decisões e ações humanizadoras de cuidados com os ciganos.

Sugiro que sejam refletidas, amadurecidas e talvez desenvolvidas pela Enfermagem algumas formas de intervenção baseadas no modelo teórico de LEININGER com os ciganos, onde proponho:

Preservação do Cuidado: Os traços e rituais religiosos, os valores culturais, modo de vida, aspecto legal, devem ser preservados e entendidos pela equipe da Enfermagem.

A equipe de Enfermagem poderia preservar o ritual de purificação no período de "marimê" acompanhando a "puérpera" em seu ritual e prática de cuidado, assim como o uso de ervas e plantas medicinais em seus cuidados e de sua valorização na ação cuidadora de aleitamento materno.

A identidade cultural poderá ser trabalhada com as enfermeiras para buscar a congruência e compreensão de sua prática.

Acomodação do Cuidado: Embora o cigano tenha sua sabedoria e seu modo de vida fortemente marcados e dominados pela presença da Bába, poderia ser tentada a negociação da diminuição da quantidade de pimenta na alimentação e do fumo, visto que alguns ciganos têm problemas de úlcera e de coração; onde BRUNNER \& SUDDART (1987) relatam que entre as diversas causas das úlceras gástricas ou pépticas, estão os fatores predisponentes como o comer irregularmente e fumar excessivamente; sendo que entre os objetivos do tratamento para evitar a supersecreção e a hipermotilidade no trato gastrointestinal, está a minimização da dieta, evitando por exemplo temperos, especialmente a pimenta. A utilização do sabão na higienização no período de: luto poderia ser negociada ou ajustada aos hábitos de saúde e de vida dos ciganos.

Reestruração do Cuidado: Percepção de doença no tocante a hospitalização com a ida de todo o clã ao hospital; a infermeira poderia mostrar que isso de certa forma a prejudica, assim como dificulta a atuação da equipe profissional junto ao doente. 


\section{9 - CONCLUSÃO}

Pode-se concluir que a utilização do referencial teórico de LEININGER foi decisiva para a evolução de todo o trabalho.

Pude compreender alguns aspectos da cultura cigana, e mais, incorporar a existência de similaridades e diferenças entre práticas de cuidado, além de grande aprendizado profissional que espero ser incorporado e aplicado por profissionais de Enfermagem.

Acredito que a partir deste e de outros trabalhos, poderemos oferecer cuidados embasados nas necessidades emanadas da clientela cigana, levando assim ao alcance das perspectivas do cuidado desta cultura.

\section{REFERÊNCIAS BIBLIOGRÁFICAS:}

ALEXANDER, J.E. et al. Madeleine Leininger Cultural Care Theory. Art and Science of Humanistic Nursing. p.146-63, 1989.

ANDERSON, G.; TIGHE, B. Gypsy culture and health care. Am.J. of Nurs., v.73, n.2, p.282$5,1973$.

BODNER, A. LEININGER, M .Transcultural Nursing Care Values, Beliefs and Practices of American (USA) Gypsies. J.Transcult. Nurs. v.4, n.1, p.17-28, 1992.

BRUNNER , L.S. ; SUDDARTH , D.S. Tratado de enfermagem médico-cirúrgica . 5.ed. Rio de Janeiro Guanabara , 1987 , p.713-16: Tratamento dos pacientes com doenças gástricas e duodenais.

FERNANDES, T. I.F.E. Irmåozinhos Franciscanos de Emaús. Ponta Grossa, 1996. / Mimeografado/

GARCIA, P. O Padre Cigano. Belo Horizonte. Fumarc. 1995.

GUALDA, D.; HOGA, L. Estudo sobre teoria transcultural de Leininger. Rev.Esc.Enf. USP. v.26, n.1, p.65-73, 1992 .

LEININGER, M. Caring: an essential human need . New Jersey, Thorofare, Slack .1981. p.311: The phenomenon of caring : importance, research questions and theoretical considerations .

Cultural care: an essential goal for nursing and health care. In: NATIONAL MEETING OF THE AMERICAN ASSOCIATION OF NEPHR()LOGY NURSES AND TECHNICIANS, Philadelphia, 1983.

. A Relevant nursing theory: transcultural care diversity and universality. In: SIMPÓSIO BRASILEIRO DE TEORIAS DE ENFERMAGEM. 1, Florian6́polis , 1985Anais. Florianópolis, UFSC, 1985 (a), p.232-54.

Transcultural Care Diversity and Universality: a theory of nursing. Nurs.

Health Care. v.6, n.4, p.209-12, 1985(b).

LUNA, L ; CAMERON, C. Leiningers transcultural nursing . In : FITZPATRICK, J. ;

WHALL,A. Conceptual Models of Nursing . 2.ed. Califórnia , Appleton Lange, 1989. cap.5, p. $227-38$. 
BRAGA, C.G. Transcultural Nursing and the Beliefs, Mettles and Background of Gypsy Population. Rev.Esc.Enf.USP, v.31, n.3, p. 498-516, dec. 1997.

It's a question of mini-ethnographic study in nursing where it is emphasized the belief of cares, mettles, way of life, world sight of a group of gypsies of origin ROM. It was exploited the theoretical referential by LEININGER for helping the understanding of this culture, visualizing proposals in procedures and decisions of care, so as to provide cares culturally congruent. The author advocates some definitions referring to the especialty of gipsy culture concerning its cultural approaches when providing care, as subsidized for future studies .

UNITERMS: Transcultural nursing. Cares. Beliefs. Way of life. Gypsies. 